\title{
Acne vulgaris: prevalence and clinical forms in adolescents from São Paulo, Brazil*
}

\author{
Ediléia Bagatin ${ }^{1}$ \\ Lilia Ramos dos Santos Guadanhim ${ }^{1}$ \\ Luiz Roberto Terzian ${ }^{3}$ \\ Mercedes Florez ${ }^{4}$
}

\author{
Denise Lourenço Timpano ${ }^{1}$ \\ Vanessa Mussupapo Andraus Nogueira ${ }^{2}$ \\ Denise Steiner
}

\begin{abstract}
BACKGROUND: Acne is a common disease in adolescents, but there are no epidemiological data for acne in Brazil.

OBJECTIVES: To estimate the prevalence and degree of acne in adolescents from Sao Paulo and study socio-demographic factors, family history and lifestyle, associated with the disease.

METHODS: Cross-sectional study with 452 adolescents aged between 10 and 17 (mean=13.3 years), students from elementary and high school, examined by 3 independent evaluators.

RESULTS: $62.4 \%$ were female, $85.8 \%$ white and $6.4 \%$ were aged 14 . The prevalence was $96.0 \%$ and increased with age - all students over 14 had acne. The most prevalent form of acne was comedonal (61.1\%), followed by mild $(30.6 \%)$ and moderate $(7.6 \%)$ papular-pustular, which affected mostly the face $(97.5 \%)$. About half of the adolescents reported family history for acne in mother or father, and $20.6 \%$ reported previous treatment for acne. There was a higher chance of presenting non-comedonal acne with increased age $(\mathrm{p}<0.001)$.

DisCUSSION: The prevalence of acne in adolescents varies widely due to the clinical features and diagnostic methods used. Adolescents whose brothers/ sisters had acne $(\mathrm{OR}=1.7-\mathrm{p}=0.027)$ and those over $13(\mathrm{OR}=8.3$ -

$\mathrm{p}<0.001$ ), were more likely to have non-comedonal acne.

CONCLUSION: This study showed high prevalence of acne in adolescents from Sao Paulo, predominantly the comedonal form on the face, with a higher chance of presenting non-comedonal acne with increased age.

Keywords: Acne vulgaris; Demographic data; Family characteristics; Prevalence; Socioeconomic factors
\end{abstract}

\section{INTRODUCTION}

Acne vulgaris is a chronic inflammatory disease of the pilosebaceous follicles, common in adolescents, characterized by comedones, papules, pustules, cysts, nodules, and occasionally scars. Its pathogenesis includes follicular hyperkeratinization, sebaceous hypersecretion due to androgen stimulation, follicular colonization by Propionibacterium acnes, immune and inflammatory responses. It affects the face, anterior chest and upper back. ${ }^{1}$

The prevalence of acne in adolescents and adults varies among countries and ethnic groups. ${ }^{2-11}$ In Australia, acne was observed in $27.7 \%$ of students' aged $10-12$ and in $93.3 \%$ of adolescents aged 16-18. A study in Peru reported a prevalence of $16.33 \%$ and $71.23 \%$, in students aged 12 and 17 , respectively. ${ }^{2}$ In

Received on 31.08.2012.

Approved by the Advisory Board and accepted for publication on 02.03.2013

* Work performed at the Department of Dermatology - Federal University of Sao Paulo (UNIFESP) - Sao Paulo (SP), Brazil.

Financial Support: Laboratório Stiefel.

Conflict of Interest: Estudo apoiado pelo Laboratório Stiefel.

Faculdade de Medicina do ABC (FMABC) - Santo André (SP), Brazil.

Private clinic - Miami, FL, Estados Unidos. 
countries including Belgium and China, prevalence in adolescents is high, about $90 \%$, while in England it is estimated at $50 \%$. It is generally assumed that acne occurs in $70-80 \%$ of adolescentes. ${ }^{12,13}$

A Chinese study observed no disease in children under 10 and a prevalence of $1.6 \%$ at the age of 10 , which increased with age, reaching $46.8 \%$ by the age of 19, then decreased progressively, and was rare in individuals aged over 50 . In this study, $68.4 \%$ of subjects had mild acne, $26.0 \%$ moderate and 5.6\% severe. Only a third of them had been treated before (39.0\% female and $29.6 \%$ males). Acne was more prevalent in adolescent men and adult women. ${ }^{1}$ Two studies in the UK reported similar results. ${ }^{4,8}$

In the US, acne is the fourth most common reason for seeking medical consultation among patients aged 11-21, and it accounts for $4 \%$ of all visits from patients aged 15-19. ${ }^{14-16}$ Different studies have shown prevalence rates ranging from $28.9-91.3 \%$ in adolescents. 2,6,14,17,18

In Brazil, acne accounts for approximately $14 \%$ of dermatological consultations and affects both genders, different ethnicities and all age groups, predominantly in the first three decades of life. ${ }^{19}$

As there are no epidemiological data on the prevalence of acne in Brazil, the objective of this study was: to estimate the prevalence and degree of acne in adolescents from São Paulo (by gender and age group); analyze the diagnostic convergence regarding acne among three dermatologists; and study sociodemographic factors, family history and lifestyle associated with the occurrence and severity of the disease.

\section{METHODS}

Cross-sectional study including 452 adolescents aged 10-17, elementary and high school students from two public and two private institutions in São Paulo, examined by three evaluators (A, B, C).

The study population lives in São Paulo city, which has 11,253,503 inhabitants, 867,351 aged 10-14, and 841,081 aged 15-19 (Source: IBGE, Brazilian Demographic Census, 2010). In addition to those born in the city, there are citizens from all regions of Brazil, as it is the greatest economic and industrial center in the country, with numerous employment opportunities, as well as a large number of academic and cultural options. However, because of its size and heterogeneous living conditions, many social problems exist. It is estimated that there are 2,895 public schools and 2,748 private schools. Regarding elementary education, 644,804 students are registered at public schools and 137,024 at private schools; while the numbers for high school are 380,035 students at public schools and 78,274 at private schools (Source: School Census MEC / Inep and Educational Information Center of State
Department of Education - 2008).

The sample size was based on Rademaker's study (1989), ${ }^{20}$ in which the prevalence of acne in girls ranged from $61 \%$ at the age of 12 , to $83 \%$ at the age of 16 and, for boys, the equivalent rates were $40 \%$ and $95 \%$, respectively. Assuming an average prevalence of acne of $50 \%$, at a confidence interval of $95 \%$, and a maximum error of $\pm 7.5 \%$, the estimated sample was of 171 adolescents from each gender. Taking into account a possible loss of $50 \%, 257$ male and 257 female adolescents were necessary.

Three reviewers assessed the presence or absence of acne and its characteristics: clinical form (comedonal, papular-pustular - mild, moderate or severe, nodular-cystic - moderate or severe), age of onset, location (face, trunk or both) and treatment (age, duration and medication used). ${ }^{21}$ The characteristics of parents (education, previous history and age of onset), socio-demographic factors and lifestyle conditions of the adolescents (age, gender, race, current school grade, smoking and age of onset of smoking), were also analyzed. For girls, the age of menarche and oral contraceptive use were considered.

Agreement between the three evaluators was gauged using kappa statistics (for presence or absence of acne) and weighted kappa statistics (for the degree of acne). Agreement is considered moderate when $0.4 \leq \kappa<0.6$, good when $0.6 \leq \kappa<0.8$ and very good (almost perfect) when $\mathrm{k} \geq 0.8$.

The prevalence of acne, according to sex and age, was estimated at a confidence interval of $95 \%$ (CI $=95 \%$ ). Factors associated with the occurrence of acne were analyzed via the association test, using the chisquare test.

Upon analysis of factors associated with severity of acne, the dependent variable was the disease form (comedonal or non comedonal) and the independent variables were gender, age, skin color (white, black/brown and yellow), education levels of father and mother, occurrence of acne and acne scars in parents, and smoking. This analysis was conducted by the association chi-square test or chi-square test for trend and multiple logistic regression model. The final result was assessed by the Hosmer-Lemeshow test.

The variables, presence of acne and acne scars in parents were selected to illustrate the possible role of genetic factors in the development and severity of the disease. We also planned to correlate parents' educational levels with willingness to seek medical treatment.

The double entry software Epi-Info (version 6.04) was used to treat all data, while consistency was assessed through the validate command. Afterwards, the databases were exported to the extensions xls (Excel) and sav (SPSS), using the StatTransfer software (version 2001 for Windows). 
In all analyses, we used SPSS for Windows (version 12.0) and the significance level considered was $5 \%$.

\section{RESULTS}

In order to analyze diagnostic convergence for acne among the three evaluators, 52 students ( 27 male, 25 female) from two classrooms at one school, aged 12-15 years were randomly selected.

The comparison between examiners A and B revealed only one disagreement regarding the presence or absence of acne, and it was not possible to calculate the kappa statistic, because examiner B considered that all students had acne. In assessing the degree of acne, the weighted kappa was 0.6, showing strong agreement between the examiners.

Comparing evaluators $\mathrm{A}$ and $\mathrm{C}$, there were four disagreements concerning the presence of acne $(\mathrm{K}=$ $0.31)$ and strong agreement over the degree of acne $\left(\kappa_{p}=0.6\right)$.

The data provided by examiners $B$ and $C$ revealed five discrepancies in comparing the presence of acne, and it was not possible to calculate the kappa statistic because examiner B considered that all students had acne. There was strong agreement between examiners $\mathrm{B}$ and $\mathrm{C}$ when comparing the degree of acne $\left(\kappa_{p}=0.6\right)$.

Among the 452 adolescents evaluated, $62.4 \%$ were female, $85.8 \%$ white and $6.4 \%$ were aged 14 . The age ranged from $10-17$, with a mean of $13.3(\mathrm{SD}=2.02$ years), and median of 13.0.

Acne was present in 434 adolescents examined, i.e., the prevalence was $96.0 \%$ (CI 95\% [94.2; 97.8]). There was no difference between sexes ( $\mathrm{p}=$ 0.856): male, 95.9\% (IC 95\% [92.9; 98.9]) and female, 96.1\% (IC 95\% [93.8; 98.4]). The prevalence increased with age, but there were no differences at ages 10, 11, 12 and 13 (90.9\%, 93.3\%, 91.6\% and 95.5\% respectively, $\mathrm{p}=0,726$ - chi-square test of trend). All students over 14 had acne and therefore the confidence interval of $95 \%$ was not calculated.

Graph 1 shows that the most prevalent form of acne was comedonal (61.1\% - CI 95\% [56.5\%; $65.7 \%])$, followed by mild $(30.6 \%$ - CI 95\% [26.3\%; $34.9 \%])$ and moderate $(7.6 \%$ - CI 95\% [5.1\%; 10.1\%]) papular-pustular.

Table 1 presents a description of the location and age of acne onset. The most commonly affected site was the face $(97.5 \%)$ or the face and trunk $(2.3 \%)$. The age at which students experienced their first episodes ranged from 2 to 16 ; a mean of $11.5(\mathrm{SD}=1.6$ years) and median of 11.0, and the most prevalent age groups were 11 and 12 years (50.4\% of patients with acne).

Use of oral contraceptives was reported by only four adolescents $(0.9 \%)$. The age of menarche ranged from 8 to 15 , with a mean of $11.8(\mathrm{SD}=1.1$ years) and

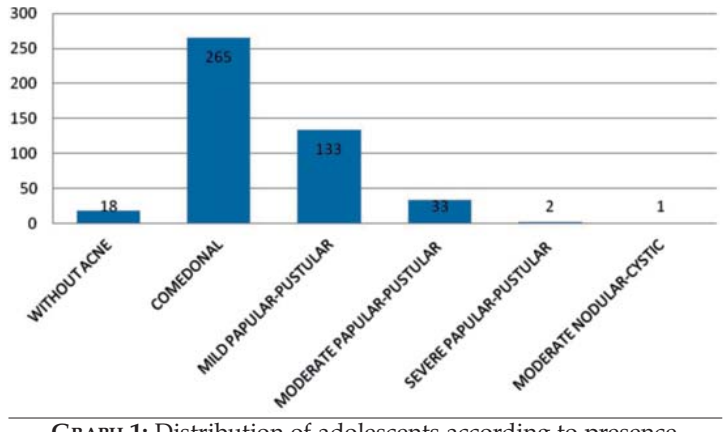

GRAPH 1: Distribution of adolescents according to presence and degree of acne

median of 12. Previous treatment for acne, such as topical products, with or without "skin cleansing" and oral medications, "skin cleansing" associated or not with pill intake, and the use of oral medications, was reported by 93 (20.6\%) of the 452 adolescents. Only 18 adolescents were able to recall the duration of the treatment, which ranged from 1 to 35 months (mean 6.3 months, $\mathrm{SD}=8.1$ months and median $=3.5$ months).

Most parents had a college degree and about half of the adolescents reported a family history of acne in mothers or fathers. Almost all reported that acne in parents occurred during adolescence. The presence of acne scars was reported in $15.3 \%$ of fathers and $13.3 \%$ of mothers (Table 2 ).

Presence of acne in other relatives was mentioned by $61.1 \%$ of the students, $32.5 \%$ in siblings, $34.1 \%$ in cousins and $14.4 \%$ in uncles/aunts.

Given that all teenagers over the age of 14 had acne, analysis of associated factors was restricted to those aged 10-13. There was no difference in acne prevalence regarding skin color $(92.1 \%, 100.0 \%$ and 93.3\% for white, black / brown and yellow, respectively, $\mathrm{p}=0.371)$, parents' educational level $(94.0 \%$ vs. $92.4 \%,=0.664$ for father and $92.4 \%$ vs. $93.0 \%, p=0.874$ for mother) and family history of acne $(96.8 \%$ vs. $90.6 \%, p=0.118$ for father; $90.6 \%$ vs. $94.2 \%, p=0.289$, for mother; $91.4 \%$ vs. $93.6 \%, \mathrm{p}=0.558$, for other relatives). At this age, no adolescents smoked and, therefore, the association has not been tested. Thus, since there was no significant association between the presence of acne and the variables studied, analysis with logistic regression models was not continued.

As there were few cases of non-comedonal acne, lesions were classified into comedonal or noncomedonal acne. Table 3 shows a significant association between the form of acne, age and previous treatment, with a higher prevalence of comedonal acne ( $\mathrm{p}$ $<0.001$ for both). In accordance with Table 3, the chances of presenting non-comedonal acne are higher with increased age (chi-square test of trend - $p$ for trend $<0.001$ ). 
TABLE 1: Number and percentage of teenagers with acne, regarding affected area and age of onset

\begin{tabular}{llll}
\hline Affected area & No. & $\%$ & CI 95\% \\
\hline Face & & & {$[95.5 \% ; 98.6 \%]$} \\
Face and trunk & 423 & 97.5 & {$[1.3 \%, 4.2 \%]$} \\
Trunk & 10 & 2.3 & {$[0.0 \% ; 1.3 \%]$} \\
Age of onset & 1 & 0.2 & {$[4.3 \% ; 8.9 \%]$} \\
$\leq 9$ years & & 6.2 & {$[13.0 \% ; 19.9 \%]$} \\
10 years & 27 & 16.2 & {$[22.8 \% ; 31.1 \%]$} \\
11 years & 70 & 26.7 & {$[20.0 \% ; 28.0 \%]$} \\
12 years & 116 & 23.7 & {$[13.4 \% ; 20.4 \%]$} \\
13 years & 103 & 16.6 & {$[6.1 \% ; 11.3 \%]$} \\
$14-17$ years & 72 & 8.3 & {$[1.3 \% ; 4.2 \%]$} \\
Don't know & 36 & 2.2 & \\
Total & 10 & $\mathbf{1 0 0}$ & \\
\hline
\end{tabular}

TABLE 2: Number and percentage of adolescents, according to parental characteristics

\begin{tabular}{|c|c|c|c|}
\hline Father's Educational level & No. & $\%$ & CI $95 \%$ \\
\hline Incomplete Basic Education & 26 & 5.8 & {$[4.0 \% ; 8.3 \%]$} \\
\hline Basic Education & 9 & 2.0 & {$[1.1 \% ; 3.7 \%]$} \\
\hline Incomplete High School & 5 & 1.1 & {$[0.5 \% ; 2.6 \%]$} \\
\hline High School & 63 & 13.9 & {$[11.0 \% ; 17.4 \%]$} \\
\hline Incomplete College & 17 & 3.8 & {$[2.4 \% ; 5.9 \%]$} \\
\hline College & 284 & 62.8 & {$[58.3 \% ; 67.2 \%]$} \\
\hline Unkown father/ignored & 48 & 10.6 & {$[8.1 \% ; 13.8 \%]$} \\
\hline \multicolumn{4}{|l|}{ Father with acne } \\
\hline Yes. in adolescence & 144 & 31.9 & {$[27.7 \% ; 36.3 \%]$} \\
\hline Yes. in adulthood & 1 & 0.2 & {$[0.0 \% ; 1.2 \%]$} \\
\hline Unkown father/ignored & 142 & 31.4 & {$[27.3 \% ; 35.8 \%]$} \\
\hline \multicolumn{4}{|l|}{ Father with acne scars } \\
\hline No & 333 & 73.6 & {$[69.4 \% ; 77.5 \%]$} \\
\hline Yes & 69 & 15.3 & {$[12.2 \% ; 18.9 \%]$} \\
\hline Unkown father/ignored & 50 & 11.1 & {$[8.5 \% ; 14.3 \%]$} \\
\hline \multicolumn{4}{|l|}{ Mother's Educational level } \\
\hline Incomplete Basic Education & 25 & 5.5 & {$[3.8 \% ; 8.0 \%]$} \\
\hline Basic Education & 16 & 3.5 & {$[2.2 \% ; 5.7 \%]$} \\
\hline Incomplete High School & 6 & 1.3 & {$[0.6 \% ; 2.9 \%]$} \\
\hline High School & 79 & 17.5 & {$[14.3 \% ; 21.2 \%]$} \\
\hline Incomplete College & 14 & 3.1 & {$[1.9 \% ; 5.1 \%]$} \\
\hline College & 284 & 62.8 & {$[58.3 \% ; 67.2 \%]$} \\
\hline Unkown mother/ignored & 28 & 6.3 & {$[4.3 \% ; 8.8 \%]$} \\
\hline \multicolumn{4}{|l|}{ Mother with acne } \\
\hline No & 189 & 41.8 & {$[37.4 \% ; 46.4 \%]$} \\
\hline Yes. in adolescence & 165 & 36.5 & {$[32.2 \% ; 41.0 \%]$} \\
\hline Yes. in adulthood & 7 & 1.5 & {$[0.8 \% ; 3.2 \%]$} \\
\hline Unkown mother/ignored & 91 & 20.1 & {$[16.7 \% ; 24.1 \%]$} \\
\hline \multicolumn{4}{|l|}{ Mother with acne scars } \\
\hline No & 368 & 81.4 & {$[77.6 \% ; 84.7 \%]$} \\
\hline Yes & 60 & 13.3 & {$[10.5 \% ; 16.7 \%]$} \\
\hline Unkown mother/ignored & 24 & 5.3 & {$[3.6 \% ; 7.8 \%]$} \\
\hline Total & 452 & 100 & \\
\hline
\end{tabular}


TABLE 3: Number and percentage of adolescents according to acne severity and characteristics of the adolescent.

\begin{tabular}{|c|c|c|c|c|c|}
\hline & $\begin{array}{l}\text { Acne } \\
\text { Inflammatory }\end{array}$ & Comedonal & OR & CI 95\% & p-value \\
\hline Gender & & & & & 0.615 \\
\hline Male & $108(39.9 \%)$ & $163(60.1 \%)$ & 1.108 & & \\
\hline Female & $61(37.4 \%)$ & $102(62.6 \%)$ & 1.000 & & \\
\hline Age (Years) & & & & & $<0.001$ \\
\hline $10 / 11$ & $11(11.7 \%)$ & $83(88.3 \%)$ & 1.000 & & \\
\hline 12 & $22(22.4 \%)$ & $76(77.6 \%)$ & 2.184 & {$[0.993 ; 4.802]$} & \\
\hline 13 & $20(47.6 \%)$ & $22(52.4 \%)$ & 6.860 & {$[2.865 ; 16.423]$} & \\
\hline 14 & $23(47.9 \%)$ & $25(52.1 \%)$ & 6.942 & {$[2.978 ; 16.181]$} & \\
\hline 15 & $45(58.4 \%)$ & $32(41.6 \%)$ & 10.611 & {$[4.888 ; 23.036]$} & \\
\hline 16 & $18(56.2 \%)$ & $14(43.8 \%)$ & 9.701 & {$[3.790 ; 24.831]$} & \\
\hline 17 & $30(69.8 \%)$ & $13(30.2 \%)$ & 17.413 & {$[7.044 ; 43.043]$} & \\
\hline Skin color & & & & & 0.912 \\
\hline White & $146(39.4 \%)$ & $225(60.6 \%)$ & 1.000 & & \\
\hline Black/Brown & $15(36.6 \%)$ & $26(63.4 \%)$ & 0.889 & {$[0.456 ; 1.735]$} & \\
\hline Yellow & $8(36.4 \%)$ & $14(63.6 \%)$ & 0.881 & {$[0.360 ; 2.151]$} & \\
\hline Smoking & & & & & 0.198 \\
\hline No & $163(38.4 \%)$ & $261(61.6 \%)$ & 1.000 & & \\
\hline Yes & $6(60.0 \%)$ & $4(40.0 \%)$ & 2.402 & {$[0.668 ; 8.640]$} & \\
\hline Previous Treatment & & & & & $<0.001$ \\
\hline No & $118(34.6 \%)$ & $223(65.4 \%)$ & 1.000 & & \\
\hline Yes & $47(55.3 \%)$ & $38(44.7 \%)$ & 2.337 & {$[1.443 ; 3.786]$} & \\
\hline
\end{tabular}

p: test Chi-square test

Gender, ethnicity and smoking did not reveal a significant association with acne type ( $p>0.05$ for all).

Table 4 demonstrates a significant association between the severity of acne and parents' educational level ( $p=0.008$ for father and $p=0.001$ for mother), with a higher prevalence of non-comedonal acne among those who had studied up to high school level. There was also a significant association between noncomedonal acne and the presence of the disease in siblings $(p=0.002)$, and no significant association regarding family history in fathers $(\mathrm{p}=0.052)$, mothers $(\mathrm{p}=$ $0.085)$, uncles $(p=0.942)$ and cousins $(p=0.365)$.

Table 5 presents the results of multiple analyses. Independent factors associated with the severity of acne were age and the presence of brothers/sisters with acne, adjusted according to mothers' educational level. Adolescents whose brothers/sisters had acne and those over 13 were more likely to have non-comedonal acne.

\section{DISCUSSION}

The prevalence of acne in adolescents varies widely in different studies, especially due to the clinical features and methods used, namely interviews and/or clinical examinations by a dermatologist.
Clearly, patients' perception of acne does not always correspond to the diagnosis made by the doctor, which explains discordant results when such comparisons are made..$^{22}$ Moreover, we share the opinion of some authors that the presence of open or closed comedones, in any location, is sufficient to consider the diagnosis of acne..$^{23}$ Others defend that the presence of more than 20 lesions, including inflammatory ones, is required for the diagnosis. ${ }^{24}$ A study with 4,191 subjects revealed an acne prevalence rate of $68.5 \%$ in boys and $59.6 \%$ in girls, with the presence of one comedone considered suffiecient for the diagnosis. Another study encompassing 914 patients, described a prevalence rate of only $27.9 \%$ for boys and $20.8 \%$ for girls. ${ }^{23}$ The average prevalence rate in adolescents ranges from 70 to $87 \%$, without significant differences between countries. ${ }^{23}$

In this study, the three evaluators diasagreed on the diagnosis of acne. One reported that all adolescents had acne. The presence of acne ranged from 90 to $100 \%$ among the three examiners, and the average prevalence was $96 \%$, higher than previously reported in the literature. ${ }^{23}$ The examiners agreed on the severity of acne, with a predominance of the comedonal form. 
TABLE 4: Number and percentage of adolescents according to acne severity and characteristics of parents and other relatives. p: test Chi-square test

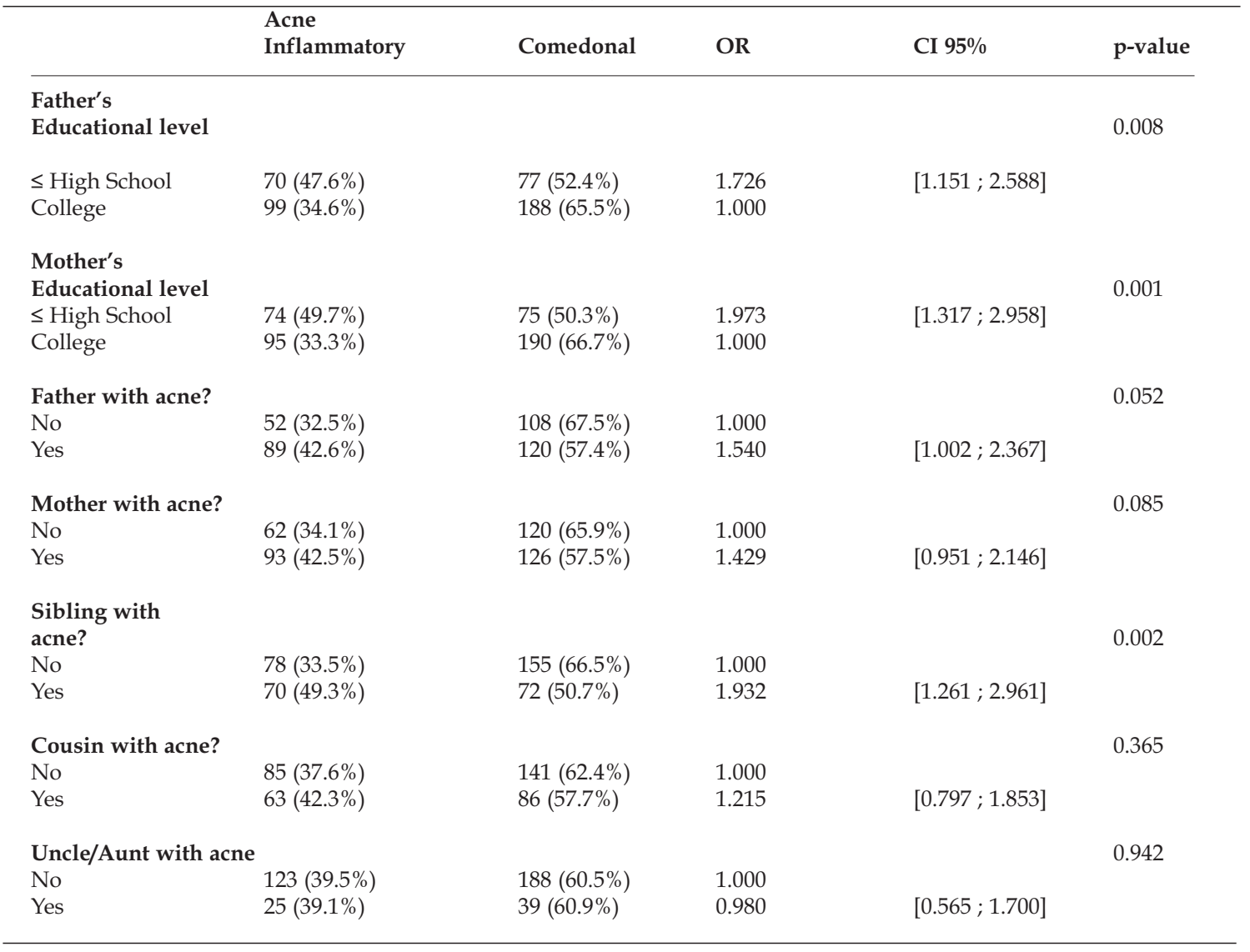

A study that analyzed gender and age demonstrated that, among girls, $61 \%$ had acne at the age of 12 , and $83 \%$ at 16 , with higher incidence between the ages of 15 and 17. Among boys, the prevalence of acne was $40 \%$ at the age of 12 , but increased to $95 \%$ at 16 , with a peak between 17 and 19 years. ${ }^{20,23}$ Our analysis found that the prevalence of acne in male adolescents was $95.9 \%$, with no difference in female adolescents $(96.1 \%)$, which increased with age.

Ninety three $(20.6 \%)$ of the 452 adolescents evaluated, reported previous treatment for acne. A study in New Zealand showed that $67.3 \%$ of the students surveyed reported having acne and significantly more difficulty in accessing medical treatment, compared with those who did not mention acne (46.0\% vs. $13.3 \%$, OR 5.29). These differences persisted after controlling for socioeconomic factors. ${ }^{17}$

Acne in younger patients is predominantly non-inflammatory and differs from that observed when onset occurs later. With age, the increased pro- duction of sebum settles, favoring skin colonization by Propioniumbacterium acnes and other bacteria, which trigger immune response and the development of inflammatory lesions, such as papules, pustules, and nodules. In the young, there are follicular plugs and comedones, but the production of sebum is insufficient for bacterial growth..$^{25}$

In this study, we observed a predominance of comedonal acne up to the age of 12 and a tendency for non-comedonal acne in adolescents over 13 . Currently, it is considered that the onset of acne occurs earlier in girls (11 years) than in boys (12 years). ${ }^{12} \mathrm{~A}$ study in Brazil showed that the average age of onset of acne symptoms in females was $14.3 \pm 4.1$ years. ${ }^{19}$ Recently, studies have reported early onset of acne, at the age of 8 or 9 , in line with epidemiological data, suggesting earlier start of puberty. ${ }^{25}$

Table 3 shows an increase in the prevalence of inflammatory acne and a decreased prevalence of comedonal acne with increased age. According to 
TABLE 5: Multiple logistic regression model for factors associated with the severity of acne. $\mathrm{p}($ Hosmer-Lemeshow $)=0.546$

\begin{tabular}{lll}
\hline Age (years) & OR Adjusted & $\begin{array}{c}\text { p-value } \\
<0.001\end{array}$ \\
\hline $10 / 11$ & & \\
12 & 1.0 & 0.061 \\
13 & 2.2 & $<0.001$ \\
14 & 8.3 & $<0.001$ \\
15 & 7.1 & $<0.001$ \\
16 & 10.1 & $<0.001$ \\
17 & 9.4 & $<0.001$ \\
& 17.0 & \\
Mother's Educational level & & \\
$\leq$ High School & 1.5 & \\
College & 1.0 & \\
Siblings with acne? & & \\
No & & \\
Yes & 1.0 & \\
\hline
\end{tabular}

Table 5, adolescents over 13 were more likely to have non-comedonal acne. This study, along with others, therefore confirms a higher severity of acne with increased age. ${ }^{25}$

There is a possible bias in this cross-sectional study. From the age of 13, the chances of presenting inflammatory acne increased and, after $14,100 \%$ of the adolescents were diagnosed as having acne. Acne severity usually increases with age. As the severe forms are more persistent, the incidence of acne may be higher when older students are examined.

Regarding the affected area, a study conducted in five US cities noted that approximately $50 \%$ of patients with acne vulgaris experienced lesions on the trunk and/or back, while over 3\% had lesions only on the trunk. Approximately 1 in 4 patients did not mention the presence of acne in the trunk that was detected by clinical examination. Most cases of acne vulgaris on the trunk were mild to moderate in severity, and over $75 \%$ were interested in treatment for trunk lesions. ${ }^{26}$ In constrast, our study reported acne on the trunk in $2.5 \%$ of the adolescents, and the face was the most frequently affected site $(97.5 \%)$.

An epidemiological study conducted in French schools, comprising 913 adolescents aged 11-18, reported that $16 \%$ of those with acne had positive family histories for acne in their fathers, versus $8 \%$ of those without acne. ${ }^{23,24}$ The equivalent data with respect to mothers was $25 \%$, versus $14 \%$ of those without acne. Among adolescents with acne, $68 \%$ of brothers and sisters also had acne, versus $57 \%$ in those without the disease. It is known that family history of acne in parents is most often associated with severe acne or weaker response to oral drugs such as cyclins. ${ }^{23}$ About half of the patients reported a parent with history of acne, almost all during adolescence, but there was no significant correlation between the presence of acne in adolescents and fathers $(p=0.052)$ or mothers $(p=0.085)$. The risk of inflammatory acne, although slight, was greater among adolescents whose siblings had the disease, which is consistent with the literature and probably related to genetic factors. The same pattern was observed in relation to lower educational levels of parents, which may mean less concern with the disease or greater difficulty in accessing early treatment.

This study demonstrated the presence of moderate and severe inflammatory acne in $8.3 \%$ of adolescents, which is lower than that reported in the literature (around 20\%). ${ }^{12}$ The occurrence of these forms ranged from $14 \%$ in Iran and $48 \%$ in Singapore. ${ }^{12,13}$

A Brazilian study that evaluated the prevalence of dermatosis in school children aged 7-14, found prevalence rates of $9 \%$ and $11 \%$ for comedonal acne, and $19 \%$ and $5 \%$ for papular-pustular acne, respectively, in public and private schools. ${ }^{27}$ In our study, there was no difference in prevalence between public and private schools.

Limitations of this study include the sample size and characteristics of the selected population. Multicenter studies should be conducted to estimate the prevalence of acne vulgaris in Brazil.

\section{CONCLUSION}

This study revealed a high prevalence of acne in adolescents from São Paulo, Brazil, with a higher prevalence of the comedonal form. Up to the age of 12, we observed a predominance of comedonal acne and a tendency for non-comedonal acne in adolescents over 13. The only factor that determined the presence of the disease was age, since $100 \%$ of the adolescents over 14 were diagnosed with acne vulgaris. 


\section{REFERENCES}

1. Shen $Y$, Wang T, Zhou C, Wang X, Ding X, Tian S, et al. Prevalence of acne vulgaris in chinese adolescents and adults: a community-based study of 17,345 subjects in six cities. Acta Derm Venereol. 2012;92:40-4.

2. Kilkenny M, Merlin K, Plunkett A, Marks R. The prevalence of common skin conditions in Australian school students: 3. acne vulgaris. Br J Dermatol. 1998;139:840-5.

3. Freyre EA, Rebaza RM, Sami DA, Lozada CP. The prevalence of facial acne in Peruvian adolescents and its relation to their ethnicity. J Adolesc Health. 1998;22:480-4

4. Cunliffe WJ, Gould DJ. Prevalence of facial acne vulgaris in late adolescence and in adults. Br Med J. 1979;1:1109-10.

5. Yahya H. Acne vulgaris in Nigerian adolescents - prevalence, severity, beliefs, perceptions, and practices. Int J Dermatol. 2009;48:498-505

6. Smithard A, Glazebrook C, Williams HC. Acne prevalence, knowledge about acne and psychological morbidity in mid-adolescence: a community-based study. $\mathrm{Br} J$ Dermatol. 2001;145:274-9.

7. Yeung CK, Teo LH, Xiang LH, Chan HH. A community-based epidemiological study of acne vulgaris in Hong Kong adolescents. Acta Derm Venereol. 2002;82:104-7.

8. Goulden V, Stables Gl, Cunliffe WJ. Prevalence of facial acne in adults. J Am Acad Dermatol. 1999;41:577-80.

9. Stern RS. The prevalence of acne on the basis of physical examination. J Am Acad Dermatol. 1992;26:931-5

10. Collier CN, Harper JC, Cafardi JA, Cantrell WC, Wang W, Foster KW, et al. The prevalence of acne in adults 20 years and older. J Am Acad Dermatol. 2008;58:56-9.

11. Poli F, Dreno B, Verschoore M. An epidemiological study of acne in female adults: results of a survey conducted in France. J Eur Acad Dermatol Venereol. 2001;15:541-5

12. Dréno B. Recent data on epidemiology of acne. Ann Dermatol Venereol. 2010;137:S49-51

13. Ghodsi SZ, Orawa H, Zouboulis CC. Prevalence, severity, and severity risk factors of acne in high school pupils: a community-based study. J Invest Dermatol. 2009;129:2136-41

14. Law MP, Chuh AA, Lee A, Molinari N. Acne prevalence and beyond: acne disability and its predictive factors among Chinese late adolescents in Hong Kong. Clin Exp Dermatol. 2010;35:16-21.

15. Ziv A, Boulet JR, Slap GB. Utilization of physician offices by adolescents in the United States. Pediatrics. 1999:104:35-42.

16. Stern RS. Acne therapy. Medication use and sources of care in office-based practice. Arch Dermatol. 1996;132:776-80
17. Purvis D, Robinson E, Watson P.. Acne prevalence in secondary school students and their perceived difficulty in accessing acne treatment. N Z Med J. 2004;117:U1018.

18. Stathakis V, Kilkenny M, Marks R. Descriptive epidemiology of acne vulgaris in the community. Australas J Dermatol. 1997;38:115-23.

19. Schmitt JV, Masuda PY, Miot HA. Acne in women: clinical patterns in different agegroups. An Bras Dermatol. 2009;84:349-54.

20. Rademaker M, Garioch JJ, Simpson NB. Acne in school children: no longer a concern for dermatologists. Br Med J. 1989;298:1217-9.

21. Gollnick H, Cunliffe W, Berson D, Dreno B, Finlay A, Leyden JJ, et al. Management of acne: a report from a Global Alliance to Improve Outcomes in Acne. J Am Acad Dermatol. 2003;49:S1-37

22. Bagatin E, Kamamoto CS, Guadanhim LR, Sanudo A, Dias MC, Barraviera IM, et al. Prevalence of acne vulgaris in patients with Down syndrome. Dermatology. 2010;220:333-9.

23. Dreno B, Poli F. Epidemiology of acne. Dermatology. 2003;206:7-10.

24. Daniel F, Dreno B, Poli F, Auffret N, Beylot C, Bodokh I, et al. Descriptive epidemiological study of acne on scholar pupils in France during autumn. Ann Dermatol Venereol. 2000;127:273-8.

25. Friedlander SF, Eichenfield LF, Fowler JF Jr, Fried RG, Levy ML, Webster GF. Acne epidemiology and pathophysiology. Semin Cutan Med Surg. 2010;29:2-4.

26. Del Rosso JQ, Bikowski JB, Baum E, Smith J, Hawkes S, Benes V, et al. A closer look at truncal acne vulgaris: prevalence, severity, and clinical significance. J Drugs Dermatol. 2007;6:597-600.

27. Laczynski CM, Cestari S da C. Prevalence of dermatosis in scholars in the region of ABC paulista. An Bras Dermatol. 2011;86:469-76.

\author{
MAILING ADDRESS: \\ Denise Lourenço Timpano \\ Rua Borges Lagoa, 508 \\ Vila Clementino \\ 04038-000 - São Paulo - SP \\ Brazil \\ E-mail:denise_timpano@yahoo.com.br
}

How to cite this article: Bagatin E, Timpano DL, Guadanhim LRS, Nogueira VMA, Terzian LR, Steiner D, Florez M. Acne vulgaris: prevalence and clinical forms in adolescents from Sao Paulo, Brazil. An Bras Dermatol. 2014;89(3):428-35. 